\title{
David Kirkaldy (1820-1897) and his museum of destruction: the visual dilemmas of an engineer as man of science
}

\author{
Frances Robertson
}

Forum for Critical Inquiry, Glasgow School of Art, Scotland, UK

\begin{abstract}
This paper examines codes of representation in nineteenth century engineering in Britain in relation to broader visual culture. While engineering was promoted as a rational public enterprise through techniques of spectacular display, engineers who aimed to be taken seriously in the intellectual hierarchies of science had to negotiate suitable techniques for making and using images. These difficulties can be examined in the visual practices that mark the career of engineer David Kirkaldy. Beginning as a bravura naval draughtsman, Kirkaldy later negotiated his status as a serious experimenter in material testing science, changing his style of representation that at first sight seems to be in line with the 'objective' strategy in science of getting nature to represent herself. And although Kirkaldy maintained a range of visual styles to communicate with different audiences, making rhetorical use of several technologies of inscription, from hand drawing to photography, nevertheless, his work does in fact demonstrate new uses of the concept of objectivity in representation when up against the practices of engineering. While these might seem merely pragmatic in comparison to the ethical weight given to the discourse of objective representation in science, in the messy world of collapsing bridges and law suits, virtuous engineers had to develop various forms of visual knowledge as practical science. This was not 'applied science' but a differentiated form of enquiry whose complexities hold as much interest as the better known visual cultures of late nineteenth century science or art.
\end{abstract}

In the nineteenth century, spectacular exhibitions of engines and machine drawings promoted engineering as both a profitable commercial enterprise and as a form of disinterested rational enquiry through events such as the Great Exhibition of 1851 that showed off engineers as 'heroes of invention'. In this public arena, however, engineers were embroiled with other professional groups who had differing aims and values. As a result of the various alliances they had made on the one hand with men of science and on the other with civil servants in charge of state policy for technical and design education, engineers were in an ambiguous position. In their approaches to visual representation they were used to expressing their creative prowess through artistic means, but they also worried that bravura draughtsmanship was increasingly out of key with the ways in which serious science was represented. In addition, engineers were a focus for

Corresponding author: Robertson, F. (Fr.Robertson@gsa.ac.uk)
Victorian anxieties about industry such as John Ruskin's horror of the dehumanising effects of factory work, or Thomas Carlyle's warning that culture would be reduced to the 'cash nexus'. Today, engineers' fine presentation drawings from this era are shown mainly in museums of transport and technology, enjoyed by enthusiasts and steam punk aficionados, but largely ignored or treated with suspicion by many professional historians who discern their hidden 'ideological' messages. ${ }^{1}$ Furthermore, the true diversity of this visual culture remains largely hidden in libraries and archives. Although the recent publication The Arts of Industry in the Age of Enlightenment (Fox 2009) expanded on a wealth of unknown sketches and models from the earlier period of industrial development already associated with such figures of popular history as James Watt or John Smeaton, technical imagery produced later in the nineteenth century has not been so closely examined. This is creates a gap in the study of visual culture, especially because other researchers such as Lorraine Daston and Peter Galison with their consideration of the idea of 'objectivity' in science (1992 and 2007), or Martin Kemp in The Science of Art (1990) have now wakened up general readers to new ways of thinking about image making in science and art. As these researchers have described the period 1850-1900, new pictorial values came to the fore in science and art that aimed at a kind of purification of intention, signalled by the search for one true style. These new ideals might be usefully contrasted if we imagine first a gestural sketch by Van Gogh and then the graphic data laid down by the needle of a self-registering meteorological instrument. While we might find very similar wavering lines in both, the intentions behind these marks are very different, and are read differently by the viewer. Just as artists aimed to carve out a personal and recognisable expressive manner as proof of sincerity and integrity, so this was complemented by an equally 'moralizing tone' adopted by men of science as they struggled to represent the natural world in ways that appeared truthful, cool, accurate and, above all, objective. ${ }^{2}$ However, visual strategies of engineers and technical draughtsmen do not at first glance appear to fit with these ideals. Their enquiries

\footnotetext{
${ }^{1}$ For example, see Louise Purbrick (1998) 'Ideologically technical: illustration, automation and spinning cotton around the middle of the nineteenth century' Journal of Design History 11: 275-93, or Brown, John K. (2000) 'Design plans, working drawings, national styles: engineering practice in Great Britain and the United States, 1775-1945' Technology and Culture 41 (2): 195-238.

${ }^{2}$ Daston, Lorraine and Peter Galison (1992) 'The image of objectivity' Representations 40, pp. 81-128; Daston, Lorraine and Peter Galison (2007) Objectivity New York: Zone Books; and see also Hentschel, Klaus (2008) review of Objectivity in Centaurus 50: $329-330$.
} 
aimed not simply to observe the natural world, but to change it. With this goal, it was impossible to lay claim to an 'objective' discourse separate from social and cultural constraints. But that does not mean that engineers did not develop forms of visual knowledge that had integrity.

This article will examine practices of drawing for engineering in order to ask how technical representations might fit into accounts of visual knowledge we are now familiar with from the history of science. For although the social and commercial aspects of scientific enterprises are now fully recognised by historians of science, in the visual realm the notion of technology as 'applied science' still lingers in a neglect of representations. Drawing and visual communication in engineering is ambiguous, being used not simply to observe or theorise natural phenomena, but also to make and shape new things. Shifts in pictorial style adopted by engineers were nonetheless neither pragmatic nor arbitrary but instead they represented the moral and intellectual complexities of 'practical science' in action. In looking at the different visual strategies developed by the Scottish engineer David Kirkaldy (1820-1897) during his working life we can move from an individual case study to a broader insight of some of the factors shaping visual knowledge in engineering, ${ }^{3}$ both in the context of the professional rivalries of his time, and in relation to our own current perceptions of that era.

Describing natural objects, what something 'looks like' when presented to the senses, is only one aspect of visual expression. Science and engineering also create knowledge through images such as diagrams or models of theoretical structures. ${ }^{4}$ In practising the art of 'directing the great sources of power in Nature for the use and convenience of man', 5 engineers did not just observe natural structures, or put forward theories about them, but in addition they aimed to build new forms with strengths and weaknesses whose behaviour would not be fully known until they were built. Engineering knowledge was an 'intermediate mode' between the practical and the scientific. Ben Marsden has argued that William J.M. Rankine (1820-1872), Regius Professor of Civil Engineering and Mechanics at the University of Glasgow between 1855 and 1872, deliberately developed a creed of engineering as 'pure science regulated by economy', to defend his fledgling university department. Located in a major industrial city, he needed simultaneously to repel academic attacks from older established disciplines within the university whilst also recruiting students who might otherwise have gone straight into practical workshop training. The virtue of an engineer, claimed Rankine, was to recognise that knowledge in practical science had different aims from theoretical sci-

\footnotetext{
${ }^{3}$ For biographical accounts of David Kirkaldy, see Kirkaldy, William G. (1891) Illustrations of David Kirkaldy's system of mechanical testing London: Sampson Low, Marston, Searle \& Rivington, Limited; Smith, D. (1980-1) 'David Kirkaldy (1820-97) and engineering materials testing' Transactions of the Newcomen Society 52: 49-65; Day, Lance and Ian McNeil Biographical dictionary of the history of technology Volume 39, p. 402; Smith, Denis (2008) 'David Kirkaldy (1820-1897)' in Cross-Rudkin, Peter and Mike Chrimes, eds (2008) Biographical dictionary of civil engineers in Great Britain and Ireland, Volume 2: 1830-1890 London: Thomas Telford, pp. 447-448.

${ }^{4}$ See for example De Chadarevian, Soraya and Nick Hopwood (2004) Models: the third dimension of science Stanford, Calif.: Stanford University Press.

5 From the 1818 Charter of the Institution of Civil Engineers, in Buchanan, R.A. (1989) The engineers: a history of the engineering profession in Britain 1750-1914 London: Jessica King Publishers, p. 64.
}

ence, guided by the question: 'what are we to do', rather than 'what are we to think'. ${ }^{6}$ Engineers used drawings for several purposes, in many styles, to propose new structures and mechanisms and to see if they would work as intended before expensive construction work. And while drawings were used to reassure potential clients, peers and rivals, the ways in which engineers learnt to draw and use images were also a crucial element in their drive to assert personal professional standing in rivalry with other emerging professions of nineteenth century Britain. Before turning to Kirkaldy and his work, it is important to consider some of these social factors that were in play in the development of British professional lives in the nineteenth century.

\section{Making science and progress visible}

Engineers made professional claims for status on several fronts from the late eighteenth century onwards, not least as 'gentlemanly' discoverers of new knowledge in equality with men of science. These aspirations resonated uncomfortably with English social and professional hierarchies. The working practices of engineers were derived from manual craft trades, and their training as apprentices always began in the workshops, in opposition to the view that only gentlemen with a 'liberal education' could judge impartially and make trustworthy statements in the 'public sphere'. 7 Nevertheless, prejudices and practices were often at odds. In the period from 1830 onwards, 'gentlemen of science' at the University of Cambridge began to develop an interest in engineers and engineering during their campaign to seize ownership of the British Association for the Advancement of Science (BAAS). ${ }^{8}$ Engineers were recruited as allies during the formation of the BAAS in order to 'render visible' the idea of progress, with frequent exhibitions of local manufactures at annual meetings. Nevertheless, they were kept in a subordinate position, and the respect they gained was ambiguous. ${ }^{9}$ Indeed, engineers who did associate themselves with BAAS meetings and experimental enquiries, such as William Fairbairn (1789-1874), were apparently happy to collude with this subordination in order to validate the cultural claims

\footnotetext{
${ }^{6}$ Rankine, W.J.M. (1858) A manual of applied mechanics London and Glasgow: Richard Griffin and Company, p. 11; Channell, D.B. (1988) 'Engineering science as theory and practice' Technology and Culture 29: 98-103, p. 102; Marsden, Ben (1992) 'Engineering science in Glasgow: economy, efficiency and measurement as prime movers in the differentiation of a scientific discipline' British Journal for the History of Science 25 (3): 319-346, p. 342. On 'harmony of theory and practice in engineering' in academic and entrepreneurial circles in Glasgow see Smith, Crosbie and M. Norton Wise (1989) Energy and empire: a biographical study of Lord Kelvin Cambridge: Cambridge University Press.

7 Buchanan, R.A. (1983) 'Gentleman engineers: the making of a profession' Victori an studies: 407-29; Shapin, Steven (1994) A social history of truth: civility and science in seventeenth-century England Chicago: University of Chicago Press, p. 397; Yeo, Richard (1993) Defining science: William Whewell, natural knowledge and public debate in early Victorian Britain Cambridge: Cambridge University Press; Fisch, Menachem and Simon Schaffer, eds William Whewell: a composite portrait Oxford: Clarendon, pp. 117-47.

${ }^{8}$ Morrell, Jack and Arnold Thackray (1981) Gentlemen of science: early years of the British Association for the Advancement of Science Oxford: Clarendon Press, p. 266.

${ }^{9}$ Aristocratic education, especially amongst those with major landholdings to manage, often embraced engineering questions of construction, while radical and dissenting families in the entrepreneurial classes sought out the modern subjects with relevance to industry on offer in Scottish or Continental universities for their children. Bennett, Jim and Stephen Johnston (1996) The geometry of war 1500-1750 Oxford: Museum of the History of Science; Cardwell, D.S.L. (1972) The organisation of science in England London: Heinemann, pp. 32-3.
} 
of their work. So despite the overall aim of 'making science visible', engineers had to negotiate the danger that they were possibly too visible, outshining their patrons. In other words, according to Morrell and Thackray (1981), engineers like Fairbairn only managed to get their genuine scientific investigations recognised if they sheltered in the obscurity of conducting mere 'applied science'; an example as Steven Shapin (1994) has it, that 'pure science' is a concept that in origin depended on the social standing of the investigator. In the nineteenth century, observers were indeed still keenly aware of such fine differences in status between engineers and natural philosophers. For example in one guide to professional career choice from 1857, engineers were first praised as the executors of the 'system of great works now overspreading the country', but then firmly put in their place: 'very few have received anything approaching an education in their calling. They have been military engineers, intelligent foremen of works, successful builders, and land surveyors' ${ }^{10}$ But despite such sneers, by mid-century it was so longer so easy to dismiss people who worked for their living. Professional researchers and academics in science also nurtured professional ambitions of salaried careers. Ideas such as 'pure science' or 'objectivity' in image making were new values designed to augment the status and the veracity of men of science.

But just as in science, in engineering too organisations such as the Institution of Civil Engineers (founded 1818) advocated three 'professional' ends: to create specialist knowledge, to police boundaries of exclusion, and to develop means of publicity and self-presentation. Individual engineers also promoted their own status by developing and debating a science of engineering, often through the medium of illustrated descriptions of large construction projects such as the road and rail bridges over the Menai Straits produced by Thomas Telford in 1826 and Robert Stephenson in the 1840s. Such publicity was directed both to general non-expert readers and also to other professional groups claiming expertise. Even 'big names' strove to achieve professional status with their peers through an appeal to target audiences such as men of science or civil servants concerned with state policy for education in design and technical skills. In this uneven context, engineers cultivated many different personal styles; for example, through Fairbairn's allegiance to the BAAS as already noted, whilst others such as Isambard Kingdom Brunel highlighted instead their capacity for masculine daring and risk-taking. ${ }^{11}$ Professional differentiation and selfpresentation was however a fragmenting process and within engineering itself different specialisms fought for control of their fields, while elite engineers of all types vied with lower ranks. From mid-century, established engineers began to sneer at draughtsmen's artistic skills, with the Engineer magazine of 30 December 1859 belittling 'mere adventurers in drawing', or like marine engineer John Wigham Richardson, shuddering at the 'continual chatter'

\footnotetext{
10 Thomson, H. Byerley (1857) The choice of a profession London: Chapman and Hall, p. $5 ; 293-5$.

${ }^{11}$ Petroski, Henry (1994) Design paradigms: case histories and judgment in engineering Cambridge: Cambridge University Press, pp. 99-115; Marsden, Ben and Crosbie Smith (2005) Engineering empires: a cultural history of technology in nineteenth-century Britain Basingstoke: Palgrave Macmillan, p. 243.
}

of drawing office. So while earlier engineers such as Smeaton or Watt believed their professional authority depended on their own handiwork at the drawing board, later engineers began to delegate the execution of drawings to subordinates.

Visual spectacles such as the Great Exhibition of 1851, however, relied on artistic and graphic skills. Millions of visitors passed through this site, where the nature of the exhibits, press coverage and associated publications all show that elite engineers at this event achieved status as heroic individuals through visual display. ${ }^{12}$ But equally this was a moment at which engineers came up against other professional groups competing for cultural status through exhibition, whether men of science, artists or museum directors. Engineers were, for example, co-opted into various 'design reform' initiatives, dominated by the figure of the civil servant Henry Cole (1808-1882), one of the key organisers of the Great Exhibition. ${ }^{13}$ Certainly, the Exhibition did offer some elite engineers the means of getting a hearing for their ideas in scientific and government circles. For example Joseph Whitworth (1803-1887) used the exhibition to promote his ideas of standardised techniques of scientific manufacture, and of the importance of education. ${ }^{14}$ Nevertheless the very success of events such as the Great Exhibition set up conflicts of interest for engineers like Kirkaldy whose expertise lay in visual display. Kirkaldy's own works as a draughtsman had been prominent both in the London Great Exhibition of 1851 and the Paris Exhibition of 1855 as we will see, but the very recognition he was accorded in this sphere brings forward some of the dilemmas of his quest for status as a serious experimenter. While these events appeared to be nothing but good publicity, asserting and confirming engineers and designers like Kirkaldy as 'heroes of invention', this did not necessarily support Kirkaldy's ambition to develop his theoretical and scientific expertise in material testing or to recruit allies in this field.

\section{Presentation drawings and the display of engineering}

Kirkaldy began work as a bravura naval draughtsman in the shipbuilding firm of Robert Napier \& Sons, Glasgow, preparing presentation drawings as well as designing for construction on the drawing board. Unlike working drawings used to design machines or to direct workers on the shop floor, presentation drawings were given to clients, stored as company archive materials, and shown to potential customers as visualisations of a future reality. Kirkaldy, the son of a wealthy Dundee merchant, entered a late apprenticeship at Napier's Vulcan Foundry in 1843 after an earlier liberal education at Edinburgh University. There, he spent four years training in manual workshop skills before moving to the drawing office in 1847 where he

\footnotetext{
${ }^{12}$ MacLeod, Christine (2007) Heroes of invention: technology, liberalism and British identity, 1750-1914 Cambridge: Cambridge University Press; Fox, Celina (2009) The arts of industry in the age of enlightenment New Haven and London: Yale University Press, pp. 493-4.

${ }^{13}$ Cardwell (1972), pp.88-92; Bonython, Elizabeth and Anthony Burton (2003) The great exhibitor: the life and work of Henry Cole London: V\&A Publications, pp. 70-71.

${ }^{14}$ For Whitworth's 'fact-finding' trip to the U.S., see Rosenberg, Nathan, ed. (1969) The American system of manufactures: the report of the committee on the machinery of the United States of 1855 and the special reports of George Wallis and Joseph Whitworth 1854 Edinburgh: Edinburgh University Press.
} 
became chief draughtsman and calculator. Napier's drawing office had already established a style of finely wrought presentation drawings, and Kirkaldy developed further refinements. ${ }^{15}$ Presentation drawings used the same conventional linear pen and ink markings as working drawings, supplemented with watercolour washes. Watercolour shading created an illusion of three-dimensional form within the more schematic line drawing conventions of working drawings and helped non-specialists read the mechanism. Smoothly graded washes gave the illusion of light falling, creating gentle reflectivity on cylindrical machine bodies and forming applied shadows that help push projecting forms out towards us. At the same time, the use of orthographic projection, like a plan brought to life, displays all parts of the object with equal importance. In contrast to pictorial perspective that organises forms obliquely, as if from the viewpoint of one observer, orthogonal presentation is impersonal. Such images explain complex moving parts, but frozen to immobility, placing the viewer in control. As well as showing the final working out of the engine design, presentation drawings also displayed artistic skills of perspective construction and painterly judgment, and in comparison to surviving presentation drawings from other hands, ${ }^{16}$ Kirkaldy pushed the conventions of this style to an extreme to create aesthetic impact. His lines were exceptionally narrow and unvarying, and the effects of light were systematically, indeed obsessively, rendered, using a range of illusionistic devices. Shadows, highlights and reflected light all helped towards creating a powerful, hyperreal effect, with complex forms and their shadows calculated in accord with the finessing urged in draughtsmen's handbooks. ${ }^{17}$ However, although these images looked real, they were all illusion. They were not based on observation, but were fantasy visualisations of perfect mechanical servants that in reality would be much more messy and unreliable.

Kirkaldy's skills as a draughtsman were displayed far beyond the confines of the factory and its circle of clients and visitors. His work was reproduced as steel engravings in The Imperial Cyclopaedia of Machinery, a souvenir of the London Great Exhibition of 1851 (Figure 1), and in a further and equally imposing illustrated publication, timed to coincide with the Paris Exhibition of 1855, where Kirkaldy's original drawings were also on show as presentation gifts to Napoleon III. Finally, Kirkaldy also exhibited his drawings of the 'Persia' iron ship at the Royal Academy in $1861 .^{18}$

\footnotetext{
${ }^{15}$ For an example of the Napier style see Baynes, K. and Pugh, F. (1981) The art of the engineer Guildford: Lutterworth, p. 15.

16 The most well known and accessible holdings include The Boulton \& Watt Archive held by Birmingham Central Library, and the Nasmyth \& Gaskell archive at the Institution of Mechanical Engineers (IMechE) London, and the many examples in Baynes and Pugh (1981)

${ }^{17}$ See for example Johnson, William (1853) The practical draughtsman's book of industrial design: forming a complete course of mechanical, engineering, and architectural drawing translated from French of Armengaud, ainé, Professor of design at the Conservatoire Nationale des Arts et Metiers, and Armegaud jeune, and Amouroux civil engineers, rewritten and arranged with additional matter and plates, and contemporary references and examples London: Longman \& Co., pp. 96-108.

${ }^{18}$ Kirkaldy, David (1855) Machinery of the British \& North American Royal Mail steam ship 'Arabia' and of the West India Royal Mail steam ship 'La Plata', constructed by Robert Napier, Esq. Glasgow: William Mackenzie; Kirkaldy, (1891), p. 266; Graves, A. (1905) Royal Academy of Art, dictionary of contributors 1769-1904 London: Henry Graves \& Co. Ltd. Volume 2, p. 33. The Imperial cyclopaedia of machinery (nd 18521856) Glasgow: William Mackenzie.
}

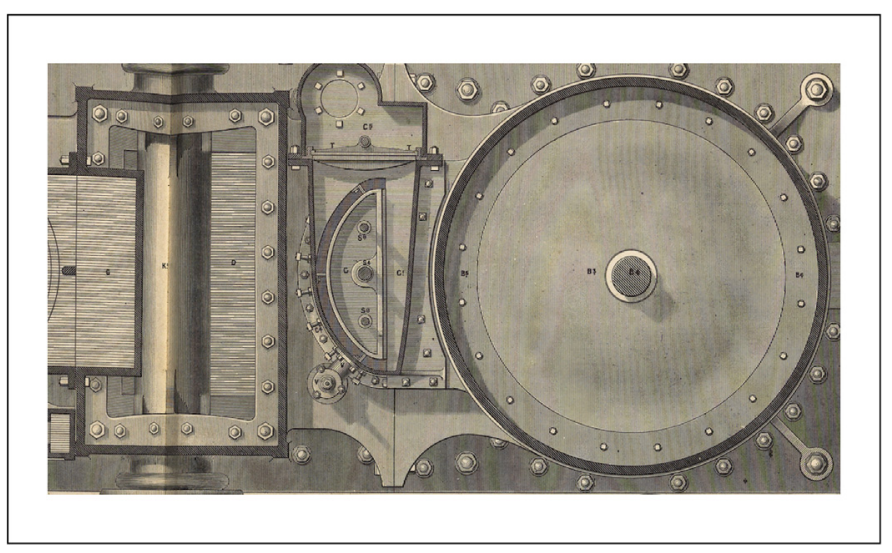

Figure 1. David Kirkaldy, detail from drawing of engine of 'La Plata' from The Imperial Cyclopaedia of Machinery. The book showed the most imposing exhibits from the Great Exhibition of 1851 in an equally dominating style, with brash use of 93 double-page spreads of steel-engraved illustrations using the technical orthographic convention of plan, section and elevation. University of Glasgow Library, Special Collections.

Despite these successes, his biography of 1891 Illustrations of David Kirkaldy's System of Mechanical Testing claimed that Kirkaldy still felt like a subordinate at Napier's and resented it. Although Kirkaldy's son William was the named author of this work, he took care to assure the reader that his father had overseen every step of the writing. Indeed, we frequently hear the outraged paternal voice breaking into the narrative, railing against 'those who have been unjust'. We read, for example, that Kirkaldy felt his research into materials and performance of vessels, propellers, engines and boilers, conducted whilst at Robert Napier \& Sons, was being thwarted by 'prejudice against his advanced ideas'. Equally, Kirkaldy's plan to exhibit his drawings of the 'Persia' at the Royal Academy exhibition of 1861 was hatched as a secret act of defiance, adding éclat to his resignation from Napier's in the same year. It was very unusual for engineers to exhibit in this bastion of fine art, and even rarer to win a prize. But at the same time as he honed his artistic persona for this feat, with the other side of his brain Kirkaldy was also pondering the correct 'moral procedure' for visualising his research into materials as he worked towards starting his own business in his London laboratory (that he called the 'museum') in 1866. His experimental work in the mechanical testing of the tensile strengths of materials evoked a second, different mode of visual expression.

\section{Material testing and visual data}

The 1891 biography was part of a lengthier work, ghosted throughout by David Kirkaldy in combative mode, promoting the family business of materials testing, and containing displays of data from twelve thousand experiments supplemented with illustrations of the workshops. Kirkaldy developed his main visual techniques for presenting complex experimental information in the period 1858-1861 during the test trials he had conducted for Robert Napier on the strength of iron plates and angle iron for the ships 'Black Prince' and 'Hector'. ${ }^{19}$ As he informs us, he agonized

\footnotetext{
19 Kirkaldy, David (1862) Results of an experimental inquiry into the comparative tensile strength and other properties of various grades of wrought-iron and steel Glasgow: Bell and Bain.
} 


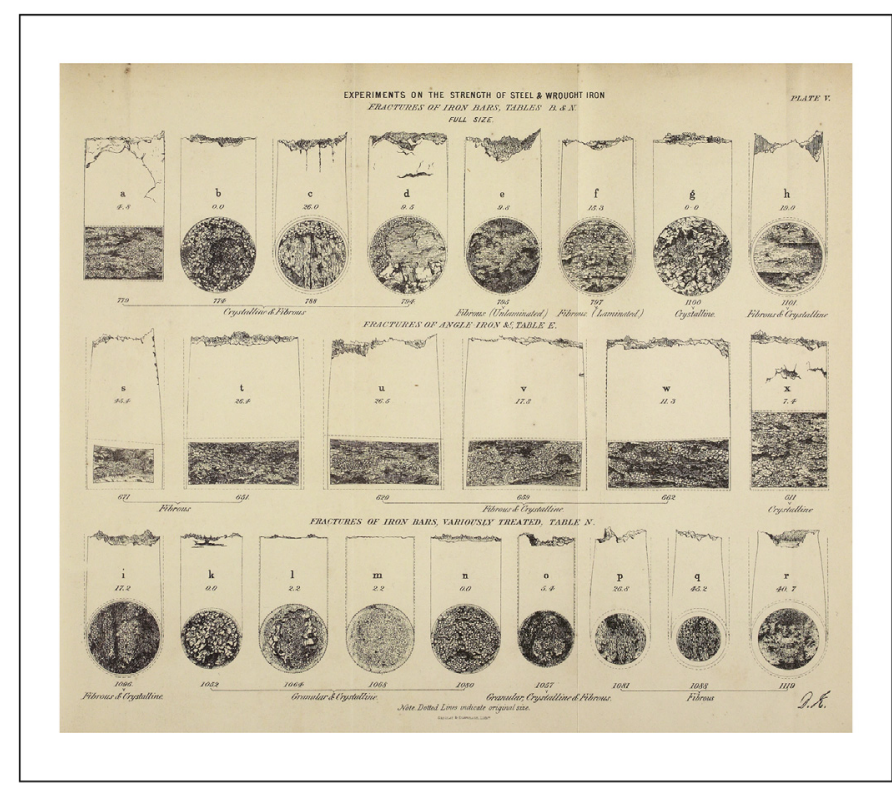

Figure 2. Plate $\mathrm{V}$ from Results of an Experimental Inquiry into the Comparative Tensile Strength and Other Properties of Various Grades of Wrought-Iron and Steel (Kirkaldy 1862). Trustees of the National Library of Scotland.

about the merits of different techniques of recording and displaying data (described as we have seen as a 'moral' quest), and eventually chose to display results as tables and graphs,${ }^{20}$ supplemented with additional observational records of the internal structure of metal after its fracture (Figure 2). Kirkaldy developed his experimental technique further in the 1860 s by cutting regular surface patterns into his specimens before testing as a visual means of sorting stress deformations in various iron and steel samples (Figure 3).

In this context Kirkaldy chose to minimise the impressive draughtsman skills he developed earlier in his career, instead contriving methods by which nature could be made to represent herself graphically in his laboratory of material testing. Although this concept of natural imagery has most often been connected to the adoption of photographic data in science in the last decades of the nineteenth century, Kirkaldy exploited the same notion in the medium of massive real-world materials such as rolled steel plate, in order to assert his status as an experimental observer, not an illusion merchant. His prowess in this new line of work was recognised by fellow engineers; for example by those who asked him to work for the Steel Committee of the Institution of Civil Engineers in the 1860s, or employed him as a consultant on major construction projects such as the St. Louis Bridge of J.B. Eads. Kirkaldy was also employed to analyse the afterlife of construction, notably as a consultant during the enquiry following the disastrous collapse of the first Tay Bridge in 1879. On the face of it, this sequence of events appears to follow a familiar trajectory of popular Victorian biography; a struggle to find a vocation and to gain agency,

\footnotetext{
${ }^{20}$ For the development of quantitative statistical graphs for the visual display of information see: Beniger, James R. and Dorothy L. Robyn (1978) 'Quantitative graphics in statistics: a brief history' The American Statistician 32 (1), pp. 1-11; Meadows, A.J. (1991) 'The evolution of graphics in scientific articles' Publishing research quarterly 7 (1), pp. 23-32; Tufte, E.R. (1993) The visual display of quantitative information Cheshire Conn.: Graphics Press.
}

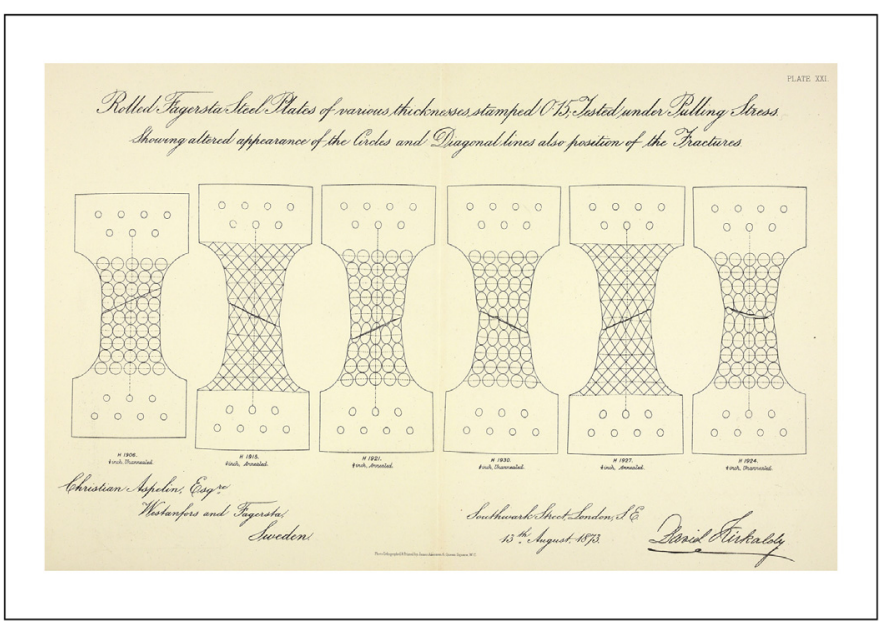

Figure 3. Rolled Fagersta Steel Plates of various thicknesses, stamped 0.15; Tested under Pulling Stress showing altered appearance of the Circles and Diagonal lines also position of the Fractures from Illustrations of David Kirkaldy's System of Mechanical Testing (Kirkaldy1891). Trustees of the National Library of Scotland.

with Kirkaldy's earlier work as a draughtsman perhaps constrained and tainted by the impurity of visual rhetoric in the service of commerce. However, in the context of the period, the implied opposition between 'objective' science and 'spectacular' engineering is misleading. Kirkaldy developed his visual strategies both as an engineer amongst colleagues and in response to techniques of exhibition and display that were developed by other occupational groups who were also grappling with questions of professional formation, self-presentation and authorship.

\section{Objectivity, understatement and the use of visual evidence}

Established preferences shown by men of science for understated drawing styles that appeared to record visual data in the simplest manner were reinforced by the promise of 'objectivity' in photographic representation after 1840. One of the most celebrated examples of changing attitudes is that of the photographic stop-motion experiments on the splash patterns of droplets when the physicist Arthur Worthington (1852-1916) was shocked to see evidence that his own inaccurate human perceptions had imposed a false pattern and symmetry on phenomena he had drawn from observation. Although men of science did not establish trust in their own modes of photography until after 1870 , nevertheless the notion that nature could be made to represent herself through this medium had considerable force. ${ }^{21}$ Bernard Lightman has described how from around 1850 onwards, elite men of science such as Charles Darwin chose to use images transcribed from photographs as visual evidence. This was in contrast to the approach of popularizers of science, aiming to keep natural theology alive', who instead chose to deploy detailed, imaginative and spectacular artistic renderings of the natural world. ${ }^{22}$ In very broad terms, such conflicts of

\footnotetext{
${ }^{21}$ Tucker, Jennifer (2005) Nature exposed: photography as eyewitness in Victorian science Baltimore: John Hopkins Press; Batchen, Geoffrey (1999) Burning with desire Cambridge, Mass.: MIT Press, p. 63; Daston, Lorraine and Peter Galison (1992) 'The image of objectivity' Representations 40, pp. 81-128.

${ }^{22}$ Lightman, Bernard (2000) 'The visual theology of Victorian popularizers of science: from reverent eye to chemical retina' Isis 91, pp. 651-80.
} 


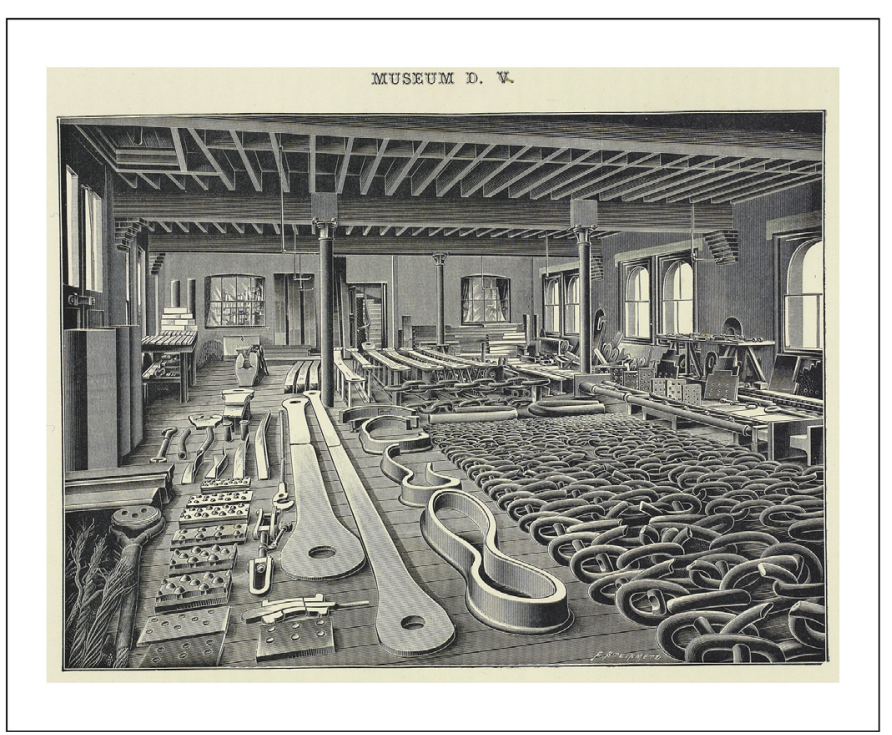

Figure 4. View of museum showing assemblies of shattered and wrecked forms after testing from Illustrations of David Kirkaldy's System of Mechanical Testing wood engraving by Messrs. Steinmetz after the photographs of H.W. Bennett (Kirkaldy1891: x). Trustees of the National Library of Scotland.

status about visual display within science might appear to place elite engineers in a dilemma. If an engineer wanted to display his professional expertise in designing and making manifest complex structures with detailed specifications, he might use arduous and detailed drawings, even though such styles merged with spectacular modes of bravura draughtsmanship. On the other hand, if he wanted to be given a serious hearing in scientific circles such as the BAAS, the Royal Society or similar learned societies, status was attached to more muted conventions.

Some aspects of Kirkaldy's stylistic break in his practice are in accord with these more objective approaches to visual representation that were gaining strength in science. For example, the image in Figure 4, from David Kirkaldy's System of Mechanical Testing shows 'Museum D' with ranks of full-sized items such as wood joists, bridge and roof links, railway-axles, ropes and cables tested in practice, reproduced in wood engraving from a photograph of the site. To our modern eyes, this image appears to be very similar to the skilled illusionism of the presentation drawing in Figure 1, but to the media-conscious reader in the photomechanical 1890s it would have been accepted as a transcription of a photograph, a factual record of experimental objects, rather than as a crafted image. ${ }^{23}$ Kirkaldy's careful captioning emphasised the photographic origin of the image, and downplayed the role of human draughtsmanship. His own role here was to commission the image, while the engraver's hand skills were swallowed up within the corporate name of 'Messrs. Steinmetz'. At one level, this 'photographic record' of the museum is simple scene setting. But storing and displaying test specimens was also an application of the photographic concept of getting

\footnotetext{
${ }^{23}$ For commentaries on the construction of trust in photographic images in print media in the decades 1880-1900 see in addition to Tucker (2005) and Daston and Galison (1992) noted above, Beegan, Gerry (1995) 'The mechanization of the image: facsimile, photography, and fragmentation in nineteenth-century wood engraving Journal of Design History (1995) 8(4): 257-74; Gretton, Tom (2005) 'Signs for labourvalue in printed pictures after the photomechanical revolution: mainstream changes and extreme cases around 1900' Oxford Art Journal 28 (3): 371-390.
}

nature to represent herself carried in to the real world, with unedited raw visual data employed as a kind of 'readymade'. ${ }^{24}$ In the museum, ranks of shattered and wrecked forms display the gradations of stress that have been applied to them, thus showing a continuity of approach with images such as that in Figure 3 in which the tested steel plates, earlier inscribed with regular patterning, now present the deformations and fractures of their carefully quantified ordeals. Hence all Kirkaldy's testing images, from graphs and tables through to the general view of the 'museum' adopt a 'realist' style that accentuates the observed data. In contrast to the sumptuous display of hand skills in the presentation drawings referred to in Figure 1, in relation to viewer expectations in its time Kirkaldy's later style was instead in accord with the concept of 'objectivity' in scientific representation, using methods of displaying visual evidence that were distanced from fallible human draughtsmanship, and closer to scientific experimental procedures.

\section{The art of construction and manufacture}

However, Kirkaldy never renounced his earlier skills. This was not due to a lack of decisiveness or integrity, but is instead an indication that the notion of objectivity can only take us so far in getting at the virtues and knowledge on show in representations of the 'practical science' of engineering. In fact, this science was necessarily piecemeal and pragmatic amongst the social, legal and material complications in play. In addition, Kirkaldy's different styles are an expression of two different branches of engineering science, on the one hand with construction, on the other with the destructive effects of wear, collapse and failure. His earlier presentation drawings, as in Figure 1, were the expression of a science of manufactures as 'kinematics' that aimed to analyse human and machine actions into simple geometrical forms. This called up a spare artistic expression that also demonstrated a science of rational control. Design and presentation drawings, however elegantly finished, are derived from this field of calculation. If this style looks abstract and airless, even at its most hyper-real, it is because it is not concerned with particularities or material qualities. The simplified geometric qualities of presentation drawings were used to unfold the technical know-how of prestigious high-capital projects, such as those of British sea power, overseen by the mechanisms of an imperial bureaucracy. Splendid technical drawings such as those made for Napier's (see Figure 1), show a different kind of 'objectivity' that is at odds with the description of 'objectivity' in scientific images addressed by Daston and Galison. Instead, in the context of factory production, the inexpressive factual quality of technical and presentation drawings takes on a controlling function as a mask for power, in accord with a bureaucratic notion of objectivity developed by Theodore Porter as 'the rule of law, not of men' developed to lend 'authority to officials who have very little of their own'. The clean and geometric operations of drawing served to assert that predictable and repeatable

\footnotetext{
${ }^{24}$ Lynch, Michael (2006) 'The production of scientific images: vision and re-vision in the history, philosophy and sociology of science' in Luc Pauwels, ed Visual cultures of science: rethinking representational practices in knowledge building and science communication Lebanon, New Hampshire: Dartmouth College Press, pp. 26-40.
} 
machine actions were the means and the end of construction and production, minimising the existence of human conflicts of the workplace. ${ }^{25}$ While Daston and Galison claim that 'mechanical objectivity' was called into being in the mid-nineteenth-century sciences to rein in the excesses of a dynamic, will-centred self that threatened to make the world in its own image, this alternative objectivity in machine drawing uses impersonality to hide the operation of the engineer's or entrepreneur's will.

\section{The science of destruction}

When we turn to materials testing, Kirkaldy's later engineering enterprise, we see a different enquiry from the mechanical science of kinematics, both in procedures and in modes of representation. Earlier systematic explorations into strength of materials had been largely undertaken by men of science or by military and naval statesponsored engineers such as Jean-Victor Poncelet in France, who theorised the effectiveness of construction in a range of real workaday situations, and the stresses of specific circumstances such as the danger of vibrations caused by the rhythmic repetitions of soldiers marching in step across a bridge. British work on strength of materials in the first half of the nineteenth century had been more localised, specific to certain projects and with the aim of selecting the right materials from those available on the market. The main standard 'ready-reference' for working engineers was Thomas Tredgold's A Practical Essay on the Strength of Cast Iron and other Metals (1822) continuing through many editions until the early years of the twentieth century, despite the fact that his work was outmoded in academic terms even by its first appearance. The closest model to Kirkaldy can be seen in the career of William Fairbairn, well-known for testing the materials and structures for Stephenson's Britannia Bridge in the 1840s, and for further investigations into this field with the BAAS and Royal Society. Like Kirkaldy, Fairbairn presented his findings in tables, supplemented with observational data, but unlike Kirkaldy, who tested specific materials for strength in relation to each other, Fairbairn's work was directed towards isolating general structural properties of materials in order to develop standardised materials and procedures. Meanwhile Kirkaldy, in a dig against 'professors' and other 'persons receiving grants of money' (projects like those of Fairbairn's, for example), examined individual specimens as self-contained, particular cases. He refused to work with laboratory bench, sized-refined, purified samples, maintaining with reason that raw materials and manmade structures are not uniform. Kirkaldy's notion of 'practical science' took into account the constant variation of raw materials available to manufacturers that needed informed personal monitoring. So in the real world conditions of practical engineering, at least two forms of

\footnotetext{
${ }^{25}$ Robert Willis, Franz Reuleaux, or W.J.M. Rankine all developed academic approaches to machine operations, as Kinematics, in the 1840s; for objectivity, see Porter, T.M. (1995) Trust in numbers: the pursuit of objectivity in science and public life Princeton, NJ: Princeton University Press, pp. 74-78; for the 'factory system' as the objective science of worker control see Schaffer, Simon (1994) 'Babbage's intelligence' Critical inquiry 21, pp. 203-227; for 'pure' versus 'practical science' as a moral crusade, see Lambert, Kevin (2011) ‘The uses of analogy: James Clerk Maxwell's “On Faraday's lines of force" and early Victorian analogical argument' British Journal for the History of Science 44 (1): 61-88.
}

representation were needed, one suitable for universal general principles such as machine actions, the other suited to scrutinising and comparing many diverse examples.

Instead of the constructive and generalising aims of kinematics, experimental materials testing developed techniques of destruction, for this science was concerned, even obsessed, with the failure of construction and industrial production, and with good reason. Knut Styffe, the Director of the Technological Institute of Stockholm cautioned his students in 1869 , 'the lives of daily travellers are at the mercy of iron and steel'. The failure of these materials caused some spectacular disasters in railways, ships and bridges in the nineteenth century. Railway bridges of course combined these dangers, so that when railroad engines and their train of heavy wagons shuddered their many wheels across hundreds of sleepers, the problem of marching feet was magnified to a frightening extent. ${ }^{26}$ To combat these fears, projects such Stephenson's Britannia Bridge had as already noted incorporated strenuous testing during the design period. The completed bridge, although 'hailed as a tremendous structural success' that 'stood for 120 years as a monument to its engineer' was, according to Henry Petroski, really an expensive failure that demonstrated a foolish 'tunnel vision' dictated by the test results. The paradox of that close focus on the danger of failure meant that almost every other design factor such as cost or amenity for users was neglected, so that later travelers came to dread the 'hellish', clangorous experience of crossing, likened to speeding through an overheated unswept chimney. If kinematics, the 'geometry of machines', was a product of its social and political context, so too was the science of materials testing. Railway expansion and railway accidents provided a testing ground for British law in this period, and a prompt for subsequent regulation of the engineering industry by government experts from the mid-nineteenth century. ${ }^{27}$

In terms of visual style, materials testing, a science of destruction, was in contrast to the science of mechanics. Instead of abstract and general forms, in Kirkaldy's hands this science was concerned with particularities and localities. Iron and steel, like wine, each had a tincture of its own 'terroir' or region, and behaved differently under stress. Processing mattered too: different techniques of craft and science, such as annealing or puddling, cast iron versus wrought iron, all created testable variations. One of Kirkaldy's typical test runs, published in 1862, compared iron and steel from Essen, Prussia, against apparently similar materials from six different Yorkshire foundries; the results, graded by strength, prompted threats of lawsuits from outraged ironmasters. Testing to destruction, with its emphasis on the observation of the behaviour of materials

\footnotetext{
${ }^{26}$ Styffe, Knut (1869) Iron and steel: the elasticity, extensibility, and tensile strength London: John Murray, pp.4-9

27 By 1860 railway accidents were a focus for expensive liability claims, see Kostal, R.W. (1994) Law and English railway capitalism 1825-1875 Oxford: Clarendon Press, pp. 313-321; for government commissions in the wake of disasters such as the collapse of railway bridges over the Dee in 1847 and the Tay in 1879, see Parris, Henry (1965) Government and the railways in nineteenth-century Britain London: Routledge and Kegan Paul, or Buchanan, R.A. (1988) 'Engineers and government in nineteenthcentury Britain' in Roy MacLeod, ed. Government and expertise: specialist administrators and professionals, 1860-1919 Cambridge: Cambridge University Press.
} 
from specific places and manufacturing processes, gave visual form to the concept of a practical science of engineering in the social world. By displaying the deformations of individual specimens of materials under stress Kirkaldy exhibited both the disinterested scientific virtue of objective visual record, and a technique for developing public accountability.

\section{The virtues of practical engineering}

Kirkaldy constantly added new specimens to his 'museum of fractures', and combined both his visual styles with considerations of commercial exhibition display by showing specimens and reports from his own business at the Paris and Vienna Exhibitions of 1867 and 1873 respectively. Many engineers in the nineteenth century developed diverse visual styles to present their knowledge and themselves. In Kirkaldy's case this involved pondering scientific and entrepreneurial virtues in order to find the correct 'moral procedure' that he then maintained in die-hard fashion. Kirkaldy's example shows that Eugene Ferguson's well-established notion of a distinctively non-verbal 'intellectual component of technology' already conceived within the 'mind's eye' of the engineer does not fully address the complexity and variety of how knowledge was made and defended by visual means in engineering. Equally, though, in this relatively unexamined area of visual representation, we can see new ways of using and testing the notion of objectivity that has come to be established in the study of representations in science. In comparison to ideas of authenticity and purification we find in descriptions of visual representations in art and science Kirkaldy's example suggests that finding several styles and knowing how to apply them was a virtue of 'practical science'. The value that was given to engineering knowledge came into collision with different modes of theoretical science and practical science in different locations in Britain at a time when working scientists were asserting a notion of 'pure science' to defend their own professional expertise. Although Kirkaldy was undoubtedly a one-off, prickly 'Scotch thistle' depicted (admiringly) by the American Engineer in 1882, his example illustrates the wider context, and the dilemmas, faced by those claiming knowledge and virtue in the exhibition and representation of practical science, and the interest of this field of visual studies. 